\title{
PARRA EL SEMIONAUTA (ITINERARIOS EN EL PAISAJE DE LOS SIGNOS)
}

\author{
PARRA THE SEMIONAUT (ITINERARIES \\ IN THE LANDSCAPE OF SIGNS)
}

\section{MÁAGELES PÉREZ LÓPEZ*}

\section{RESUMEN}

Si se analiza en conjunto la producción de Nicanor Parra (en la medida en que eso es posible para una obra capaz de cuestionarse permanentemente a sí misma), resulta muy significativa la mutación a la que se ven sometidas sus diversas propuestas (antipoema, artefacto, artefacto visual, videoartefacto) y la importancia que adquiere en ellas la dimensión visual, que apunta a la transformación de la antipoesía en relación con la actual cultura de la imagen. Analizar su obra y en especial los videoartefactos a la luz de categorías recientemente establecidas por la crítica, en particular la de sujeto radicante de Nicolas Bourriaud, permite proponer que Parra es semionauta en la medida en que, a través del nomadismo y la mutación de las formas, produce itinerarios en el paisaje de los signos.

Palabras clave: Antipoesía, Nicanor Parra, videoartefacto, radicante, Nicolas Bourriaud.

\section{ABSTRACT}

When the work of Nicanor Parra is analysed as a whole (to the extent that this is even possible for work that is capable of permanently questioning itself), we can appreciate the significance of the mutations to which his diverse projects are subjected (antipoems, artefacts, visual artefacts, video-artefacts) and the importance that the visual element takes on in them, pointing towards a transformation of anti-poetry in relation to our current image-based culture. An analysis of his work, especially his video-artefacts, in light of categories recently established by criticism, in particular Nicolas Bourri-

* Profesora titular de Literatura Hispanoamericana, Departamento de Literatura Española e Hispanoamericana, Facultad de Filología, Universidad de Salamanca. Salamanca, España. Correo: mapl@usal.es 
aud's radicant subject, allows us to propose that Parra is a semionaut to the extent that, through nomadism and mutation of forms, he produces itineraries in the landscape of signs.

Key words: Antipoetry, Nicanor Parra, video-artefact, radicant, Nicolas Bourriaud.

Recibido: 10.04.14. Aceptado: 12.06.14.

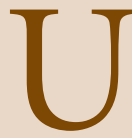

NA VISIÓN DE CONJUNTO de la producción de Nicanor Parra (si eso es posible para una obra capaz de cuestionarse permanentemente a sí misma), desearía ser una visión panóptica, a vista de pájaro, que nos permitiera captar la(s) figura(s) que traza en su totalidad (Baricco, 2008 [2006]) y a la vez funcionar como un Google Earth, o mejor, un Google Parra con el que emplear el zoom para acercarnos a algunos momentos destacados del itinerario antipoético. Sin olvidar el sentido de vigilancia disciplinaria asociado al término panóptico (Foucault, 2002 [1975]) y el desarrollo exponencial del control visual mundial (Godina Herrera, 2006), que tiende a satisfacer los objetivos del mercado y el capital, las tecnologías de la información, al mismo tiempo que nos hacen más controlables, aumentan nuestra capacidad de visión, la expanden, en términos que Vicente Luis Mora ha desarrollado en su reciente ensayo El lectoespectador (2012).

En el caso de Parra, esa visión global que me propongo ampliar permitirá advertir que la figura trazada por su proyecto es la del prefijo anti funcionando como un virus en permanente mutación ${ }^{1}$. Anti sería, así, un virus que todo lo arrasa y cuya capacidad de corrosión conocemos bien: la desacralización de las formas y los lenguajes, el cuestionamiento del mundo moderno (y también posmoderno), la parodia de la solemnidad grecolatina o el socavamiento de los paradigmas estructurales de Occidente, tanto en sus límites como en sus posibilidades. Al respecto señalaba Niall Binns que "el prefijo anti es indicativo de la intención destructiva de la antipoesía, demoledora de los mitos y de las instituciones autoritarias de la sociedad. No es sorprendente, por tanto, que la crítica parriana haya hecho hincapié en las nociones de desmitificación y desacralización” (1999: 63).

Al mismo tiempo, se trata de un virus mutante que funciona a la vez como un antivirus, pues produce su propia vacuna: la risa "gruesa", el humor satírico y paródico, la desconfianza ante el hablante, la "antipatía” (en

\footnotetext{
${ }^{1}$ Belén Gache aborda, en Escrituras nómades, la visión de William Borroughs del lenguaje como virus, puesto que se reproduce a sí mismo (2006: 39).
} 
su sentido etimológico, como negación del sentimiento o "pathos") que genera su propuesta soez, escatológica y malhablada. De ese modo, la potencia subversiva de lo antipoético, en términos del sistema literario pero también de la re-evaluación del mundo contemporáneo, participa a la vez de una doble condición: está sujeta a la deflagración de los conceptos básicos que construyeron la modernidad (utopía, progreso, libertad, desarrollo del yo), pero también desata las tensiones a las que nos vemos sometidos, a través de la risa que permite el ejercicio de la lucidez. De sus mutaciones (Baricco, 2008 [2006]) -a la vez que de sus ejes vertebradores o de sentidome ocuparé en las siguientes líneas.

\section{DEL ANTIPOEMA AL ARTEFACTO (Y SUS POSTERIORES DERIVACIONES)}

Si a partir de 1954 con la publicación de Poemas y antipoemas, el antipoema vendría a ser la contracara del poema, su reescritura en términos paródicos, de su explosión se deriva el artefacto: una forma mínima de gran potencia, próxima al chiste ("De boca cerrada no salen moscas", 2006: 348), el slogan ("La izquierda y la derecha unidas/ jamás serán vencidas", 2006: 461), el mensaje publicitario ("Dos paraísos/ por falta de uno", 2006: 512), el ensayo hiperbreve ("ACTO GRATUITO/ ordeñar una vaca/ y tirarle la leche por la cabeza”, 2006: 319), el teatro hiperbreve (“-Y TÚ TEÓFILO/Cuándo llegaste del sur-Todavía no llego del todo/ Partí el año 32/ Aún vengo de viaje/ Un sureño no termina nunca de llegar a Santiago", 2006: 442) o el relato hiperbreve ("Al tercer día/ viendo que todo se reducía a rezar/ extrajo un revólver del arca del testimonio/ -mientras decía misa-/ se dio media vuelta/ e hizo fuego sobre los fieles arrodillados", 2006: 326), entre otras posibilidades que aquí no agotamos. Su hibridez genérica lo situaría, así, en los parámetros epistemológicos de lo posmoderno (Noguerol, 1999). Como ha señalado Cristina Piña (2013), “durante la posmodernidad se anulará el principio de división que predominaba en los géneros literarios y su campo se presentará como ámbito de hibridación y experimentación”.

Los artefactos, que resultan de la explosión del antipoema según una conocida afirmación de Parra ${ }^{2}$, producen además la implosión del obje-

\footnotetext{
2 "Los antipoemas estaban cargados de pathos y tenían que reventar. Los trozos son como los fragmentos de una granada. Salen en distintas direcciones y matan a los tipos que están por ahí. Pueden considerarse 'partículas elementales' (que se caracterizan por) su alta velocidad y gran capacidad de energía. Perfectamente pueden penetrar paredes de plomo, y no por la masa, sino por la velocidad" (Calderón, 1970: 259).
} 
to libro al aparecer en 1972 como libro objeto en una caja de cartón que reunía 242 tarjetas postales ilustradas por Juan Guillermo Tejeda, quien ha indicado que compuso el texto utilizando cuatro técnicas principales: la composición tipográfica con algún elemento ornamental o de recuadro, el collage, el dibujo y la reutilización de imágenes antiguas (grabados principalmente). El resto presentaba solo la caligrafía original del antipoeta (Tejeda, 2012). El impacto de la propuesta en la desarticulación del libro como tótem de la era de Gutenberg ha sido profusamente señalado por la crítica, y el propio Tejeda ironiza afirmando que "la poesía y la gráfica unidas jamás serán vencidas"3 (2012: 27).

Ulteriores desarrollos del artefacto, que reiteran su estructura básica, dan lugar a los Chistes parra desorientar a la poesía de 1983, en los que se produce una ampliación de tonos y registros (la defensa de la ecología, la denuncia de la represión durante la dictadura de Pinochet, etc.), pero se mantiene el formato: un conjunto de 250 tarjetas postales en las que el mínimo texto verbal se conforma como chiste. Continúa, en ese sentido, la indagación profunda de Parra sobre aquellas formas que desarbolan el complejo entramado jerárquico y orgánico del objeto libro para formular espacios de creación literaria desjerarquizados e híbridos.

Con posterioridad, Parra va a trabajar diversas líneas: los sermones y prédicas del Cristo de Elqui, los discursos de sobremesa -en ambos casos de carácter exclusivamente verbal, aunque los primeros incluyan también fotografías-; algunos antipoemas cuyo carácter es también primordialmente verbal (Coplas de Navidad; Poesía política; Hojas de Parra), y una serie de piezas que conforman el Antimuseo, y en las que se hace raigalmente relevante la mutación a la que estoy refiriéndome: la transformación del paradigma verbal y su expansión, en términos de la crítica más reciente.

\section{EL ANTIMUSEO, "DIRECCIÓN OBLIGADA”}

La "dirección obligada" de la última producción parriana parece ser el Antimuseo, tal como dirá en una de sus recientes bandejitas.

\footnotetext{
${ }^{3}$ A propósito, claro está, del famoso artefacto parriano que dice "La izquierda y la derecha unidas/ jamás serán vencidas” (2006: 461).

${ }^{4}$ Con ese término, encontramos una magnífica reflexión de Gilberto Triviños en el catálogo de la exposición "Artefactos visuales" que se editó en Chile en 2002, aunque en su caso se refiere a la presencia omnipotente de la muerte en la obra de Parra y la potencia liberadora del humor.
} 


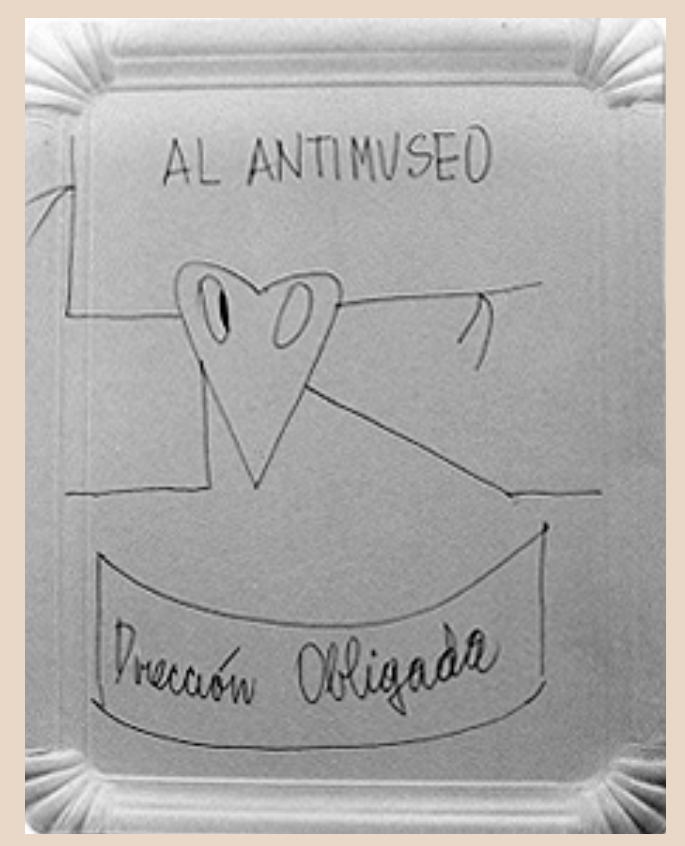

Fuente: http://www.nicanorparra.uchile.cl/fotos/index.html

Este se ha ido conformando de manera itinerante, a través de varias exposiciones: Obras públicas (poemas objeto) en el Centro Cultural de la Estación Mapocho (Santiago) en 1990; la muestra Dir poesía / Mirar poesía (1992) en la Universitat de Valencia y el Smart Museum of Art de Chicago / University of Chicago en colaboración con el poeta visual Joan Brossa; la exposición Artefactos visuales. Dirección obligada organizada por la Fundación Telefónica y presentada en Madrid (2001) y Chile (2002); la exposición Obras públicas. Ver parra creer que se inauguró en agosto de 2006 y permaneció abierta hasta octubre de ese año en el Centro Cultural Palacio de La Moneda; la realizada en 2012 en Alcalá de Henares con motivo de la entrega del Premio Cervantes o la titulada Obras públicas en la Biblioteca Nacional de España (Madrid) del 30 de mayo al 1 de septiembre de 2013, que comisarió Ignacio Echevarría. A día de hoy es un espacio en construcción que respondería al concepto de Work in progress y tiene carácter también virtual, pues es visible a través de los catálogos de las exposiciones y en especial, de numerosos vídeos en YouTube y otras plataformas así como en varias webs, en especial la de la Universidad de Chile (http://www.nicanorparra.uchile.cl/fotos/index.html). Algunas informaciones aparecidas en 
prensa han apuntado a que el antipoeta estaría trabajando para ponerlo en marcha en Isla Negra, polemizando así con Neruda al ubicarse en territorio del Nobel dentro del llamado "Litoral de los poetas".

Si Dir poesía / mirar poesía seleccionaba una parte de la obra de Parra, Artefactos visuales mostró su obra visual y objetual hasta la fecha de 2002. En el catálogo chileno de esa exposición, que comisarió Colombina Parra, se recogen los diversos formatos trabajados por el chileno: el "Quebrantahuesos" (1952) -periódico mural realizado a modo de collage junto con Alejandro Jodorowsky, Enrique Lihn y otros jóvenes, que se expuso durante varias semanas en puntos céntricos de Santiago de Chile-; los "Trabajos prácticos" (1969-) -objetos reutilizados acompañados por una breve tarjeta a modo de título o glosa, como el que se acompaña en la imagen-; las "Tablitas de Isla Negra" (1976) -tablas de madera con dibujos y/o texto a lápiz-; las "Bandejitas de La Reyna"5 (1994-) -bandejas de cartón usadas para servir comida en las que el antipoeta anota texto y/o imagen- y las "Anti-instalaciones".

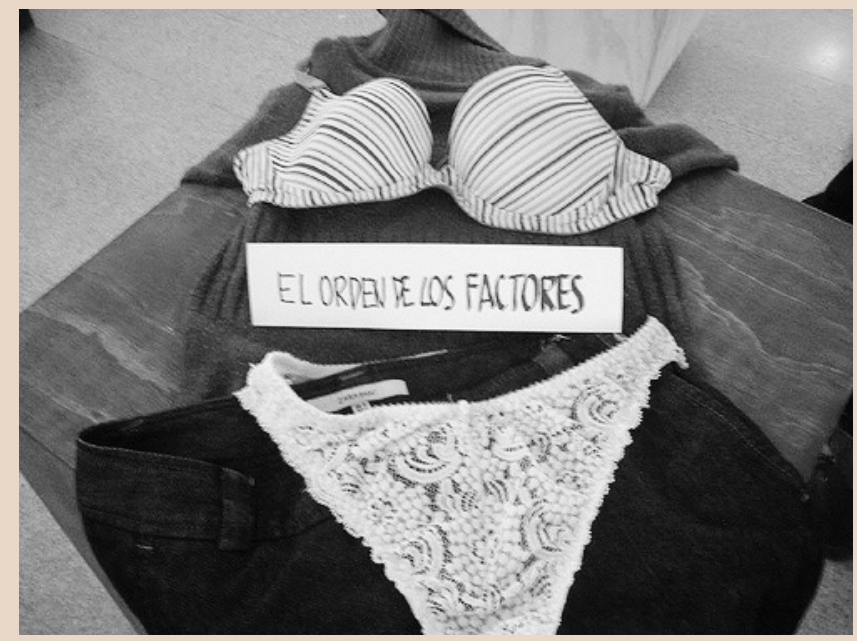

Fuente: http://www.theclinic.cl/2011/12/02/el-orden-de-los-factores/

\footnotetext{
${ }^{5}$ En exposiciones y ediciones posteriores, nombradas como "Bandejitas de La Reyna", el municipio de Santiago en el que vivió Parra.
} 
En cuanto a la exposición Obras públicas. Ver parra creer, además de los formatos ya señalados, incluía escritura sobre muros, gigantografías (los llamados "medios masivos de comunicación") y videoartefactos, serie inédita de vídeos realizados sobre textos ilustrados de Parra, que fueron presentados en pantallas junto a otras piezas de poesía visual. A modo de "artefactos dramáticos", se trata de cortometrajes de mínima duración realizados, en su mayor parte, a partir de los artefactos del autor.

En ellos se hace especialmente palpable el llamado giro icónico (Mitchell, 1994) o visual (Rodríguez de la Flor, 2011) tanto para la reciente producción cultural como literaria en sentido más estricto, en la que pueden percibirse señales del declive de la lecto-escritura a favor de la velocidad e inestabilidad acerca de su sentido con que la imagen se manifiesta. Como ha advertido José Luis Brea en su ensayo Las tres eras de la imagen (2010), en la actual "era de la (re)productibilidad electrónica"” (75-76), asistimos a la emergencia de la cultura visual entendida como "el universo lógico de las posibles formas de producir significado cultural a través de las imágenes y su circulación pública" (114).

\section{NUEVAS MUTACIONES: EL VIDEOARTEFACTO}

Con el término de "videoartefactos" hallamos una serie de vídeos que resultaron de su colaboración con Andrés Ovalle y Débora Droguett (Parra, 2011: 1136). Se visionaron en la exposición de 2006 y algunos de ellos están disponibles en la red, como es el caso de "El orden de los factores" (en la dirección de YouTube https://www.youtube.com/watch? $\mathrm{v}=\mathrm{rmWq6inOIoo),}$ o "Estación Bellas Artes" y "Artefacto dramático", insertos en un videoclip de MENALTUN titulado "Obras públicas" que está disponible en archivochile.com ${ }^{9}$ y cuya banda sonora la pone el grupo "Chancho en piedra" al versionar uno de los textos de 1954, "Sinfonía de cuna"10, en su disco "Peor es mascar lauchas" (1995).

\footnotetext{
${ }^{6}$ Una magnífica excepción la constituye el vídeo publicitario de la campaña para fomentar el consumo de leche en Chile, que protagonizó Parra con el título "Yo también tomo leche". Abre el documental que elaboró Sergio Marras (2012).

${ }^{7}$ En fecundo diálogo con la "era de la reproductibilidad técnica" de Benjamin.

8 También con la leyenda de "Vuelta al vientre materno" a la que se refiere Gilberto Triviños (2010).

${ }^{9}$ En http://www.archivochile.com/Films/np03obraspubli.avi

${ }^{10}$ Poema de la primera parte de Poemas y antipoemas (1954) que puede ser entendido como una relectura paródica de las "Canciones de cuna" de Gabriela Mistral (Pérez López, 2001).
} 
La energía radicalmente contemporánea de la antipoesía había de llevarnos a desembocar en el territorio del vídeo y el videoclip (en sentido estricto, el titulado "Obras públicas" podría serlo, al tratarse de un cortometraje musical de secuencias breves vinculado al espacio de la publicidad por su naturaleza persuasiva), pues, como ha señalado Néstor García Canclini, el videoclip sería forma por excelencia del espacio artístico contemporáneo: "Es el género más intrínsecamente posmoderno. Intergénero: mezcla de música, imagen y texto. Transtemporal: reúne melodías e imágenes de varias épocas, cita despreocupadamente hechos fuera de contexto; retoma lo que habían hecho Magritte y Duchamp, pero para públicos masivos" (2003 [1989]: 284).

En la era del presente, definida bajo el marbete general de cultura de la imagen, se subraya la preponderancia de un pensamiento en imágenes, en términos de José Luis Molinuevo (2006). En su encrucijada se sitúa la obra parriana desde hace varias décadas. El antipoeta ha sido así capaz de aprovechar la energía massmediática de la comunicación audiovisual. Si con Pérez Jiménez (1996) podemos concluir en que se ha producido el cambio metafórico que supone el paso de "la imaginación al poder" a "la imagen al poder", Parra ha articulado espacios de diálogo interartístico en los que la imagen ocupa un papel preponderante $y$, al no limitarse a un solo lenguaje, un solo medio o un solo soporte, ha sido capaz de volver porosas las fronteras entre diversos géneros y formatos, en una noción que en su momento consideré ecocrítica (Pérez López, 2003), pero que hoy merecería también el adjetivo de mutante y que puede pensarse, al menos en germen, como parte de una cultura interconectada, en red o cultura_RAM (Brea, 2007).

En este sentido resulta especialmente interesante el videoartefacto titulado "Artefacto dramático", porque evidencia la mutación de las formas a que me vengo refiriendo: en un primer momento, el artefacto de 1972 en que Tejeda había dibujado una vaca y su dueño, bajo los que se leía "ACTO GRATUITO/ ordeñar una vaca/ y tirarle la leche por la cabeza”, ejemplificando así humorísticamente el acto puro, sin motivación, que no puede ser ni juzgado ni condenado y en el que no hay culpa sino placer infantil e irreflexivo ${ }^{11}$, que constituye uno de los pilares centrales de la propuesta surrealista.

\footnotetext{
${ }^{11}$ Cfr. El siglo de los intelectuales de Michel Winock. Sería la "libertad absoluta" que preconizó André Gide.
} 


\subsection{2. \\ ACTO GRATUITO \\ ordeñar una vaca \\ y tirarle la leche por la cabeza}

(Parra, 2006: 319)

Veinte años más tarde reencontraremos este acto gratuito en el discurso de sobremesa titulado "Happy Birthday (Discurso del Caupolicán)" de $1993^{12}$, en el que leemos, en el poema (o sección) XVII, titulado "Una pregunta al compañero Gorbachov":

5

CONTAMINACIÓN

Artefacto dramático

Consiste en quemar un neumático en el escenario

A puertas y ventanas cerradas

$[\ldots]$

10

Otro artefacto dramático:

Ordeñar una vaca

Y tirarle la leche $\mathrm{x}$ la cabeza

(Parra, 2011: 629)

La ausencia de la parte visual no es concluyente, porque, como se sabe, una gran parte de los artefactos podrían prescindir de ella sin perder plenamente ni efectividad ni sentido (de hecho, han sido antologados en nume-

\footnotetext{
${ }^{12}$ Fue pronunciado el 23 de abril de 1993 en el Teatro Caupolicán de Santiago con motivo del Congreso del Teatro de las Naciones.
} 
rosas ocasiones en forma exclusivamente verbal), pero sí lo es la inclusión de la etiqueta "artefacto dramático"13, que después será retomada en el videoartefacto expuesto en el Centro Cultural Palacio de la Moneda. Por una parte, el adjetivo "dramático" apunta hacia aquello cuya naturaleza es grave, tensa o conflictiva. Por otra, no menos relevante, atiende al componente dialógico de la antipoesía, frente a la monología de gran parte de la poesía parodiada por Parra, ya que en el proyecto antipoético proliferan voces y discursos de diversa raigambre, jerarquía y naturaleza.

La transformación de este segundo "artefacto dramático" en videoartefacto -pues justamente contemplamos cómo, tras ser ordeñada una vaca, se le arroja la leche a la cabeza- nos permite proponer, con Escrituras nómades (2006) de Belén Gache, que nos hallamos ante "formas escriturarias nómades", "aquellas que no se encuentran constreñidas por modelos lineales y causales" y "deconstruye[n] la idea de una trama única, dando lugar a perspectivas de lectura múltiples" (77) en las que "la polifonía, la fragmentación y la errancia aparecen como estrategias de subversión de nociones como las de verdad o autoridad acuñadas por Occidente" (19).

Si en los Artefactos del 72 ya se percibía en Parra el giro hacia lo visual, esa mutación visual del pensamiento que generaría una categoría nueva, la del lectoespectador, es decir, el "receptor de una forma artística compuesta de texto más imagen" (Mora, 2012: 19) -puesto que la mutación del paradigma supondría el paso de la letra a la imagen o de la écfrasis al interfaz, en una fase de transformación que implica un tipo de comunicación mixta-, los "trabajos prácticos" recorren ese camino apostando por el nomadismo contemporáneo como cualidad central (Maffesoli, 2004).

En la antipoesía, por tanto, debemos ampliar al máximo el concepto de texto (siempre problematizado en Parra). El antipoeta pone en jaque el mismo sistema literario del que parte porque va más allá de los límites de lo verbal y explora las posibilidades de lo intermedial, transgenérico y visual (incluso lo audiovisual, como en los videoartefactos); de otro lado, pone en jaque el sistema artístico al que llega porque se presenta como un artista "grueso", no sofisticado, aquel que dialoga de modo a la vez irónico y dramático con la cultura de masas. Para ello participa del desarrollo tecnológico de un modo deliberadamente "primario", pues toma objetos de carácter básico (la ropa interior femenina) sobre los que interviene únicamente al disponerlos en un espacio museístico (antimuseístico) y agui-

\footnotetext{
${ }^{13}$ Hasta la fecha, hay muy poca bibliografía sobre el "artefacto dramático". Es necesario señalar los recientes análisis del profesor de filosofía Adolfo Vásquez Rocca.
} 
jonearlos con un breve texto -que propongo llamar artefacto práctico para distinguirlo del anterior-, una frase escrita en una tarjeta de papel liviana, tal como señalaron los editores del catálogo de Artefactos visuales publicado en Santiago en 2002 (en este trabajo, la frase "El orden de los factores"14).

Tanto si intentamos aprehender el proyecto antimuseístico del lado de la poética como del lado del arte, tropezamos con dificultades severas: en Parra necesitamos mirar la pieza y a la trayectoria, en una formulación que corresponde al arte conceptual y ha sido desarrollada de modo muy relevante por Nicolas Bourriaud, al que volveremos en breve.

Que el término "artefacto" titule tanto una novela de 2010 de Leanne Shapton como una revista de la Universidad de Buenos Aires surgida en 1996 a propósito del impacto de la revolución tecnológica en las artes, la ética, la vida social y subjetiva, la economía, la política y las diversas formas del conocimiento ${ }^{15} \mathrm{o}$ una muestra fotográfica de Francesc Torres sobre el $11-S^{16}$, nos permite captar hasta qué punto el proyecto de Parra está en el ojo mismo del huracán, en la encrucijada que define nuestro tiempo ${ }^{17}$, sea cual sea éste.

\footnotetext{
${ }^{14}$ Con la misma frase encontramos otro "trabajo práctico", en este caso un par de calcetines colocados por fuera de las botas (Parra, 2011: 834).

${ }^{15} \mathrm{http}: / /$ www.revista-artefacto.com.ar/

16 "Memòria fragmentada. 11-S NY. Artefactes a l'hangar 17". Barcelona, CCCB, del 9 de septiembre al 3 de noviembre de 2011.

${ }^{17}$ Tres valoraciones pueden constatar la percepción que desde el ámbito de la creación contemporánea (narrativa, poética, multimedial) se tiene de la obra de Parra: la admiración sin fisuras de Roberto Bolaño; las palabras de Juan Carlos Mestre (2011) tras la reciente concesión al antipoeta del premio Cervantes ("En términos de física cuántica, Nicanor Parra es un accidente congelado de la literatura en castellano. Esos son los accidentes que determinan el curso de la historia. En pocos casos a la lengua de Cervantes se le ha dado la vuelta como a un traje usado. Parra es esencialmente la desobediencia y el discurso lúcido contra algo más que el poder, contra el aburrimiento", para añadir a continuación que Parra ha devuelto la poesía al lugar que le habían "usurpado la retórica y la academia"); y por último, la reflexión de Agustín Fernández Mallo en "Apología del error" (2008), donde indicaba: "Supongo que la creatividad consiste en aprovechar intuitivamente los errores en tu beneficio, utilizar lo que está en los márgenes, el ruido, el residuo, como quien afirmase que ha aprendido a leer valiéndose de la mayor biblioteca del mundo: los contenedores de basura, que albergan millones de textos en los envases vacíos. Las obras importantes se han hecho a través de las anomalías, si entendemos por ello las mutaciones aberrantes producidas en una disciplina. Esa anomalía es el error que solemos desechar, la tara, el resto; un extrarradio. Es ahí donde suele hallarse el ADN de lo que damos en llamar artes. Obras maestras derivadas de errores hay muchas, Las Vegas, Nicanor Parra, Sex Pistols, Georges Perec, etcétera”.
} 


\section{PARRA EL SEMIONAUTA: HACIA UNA ESTÉTICA RADICANTE}

Si Huidobro era el paracaidista de la poesía chilena moderna, Parra será el semionauta de la del siglo XXI. Una parte importante de su última producción resulta inabordable porque juega con los bordes, los límites, los extremos hasta exacerbar una propuesta mutante (la del virus del prefijo anti) que ya estaba presente en la misma fecha del 54 con sus Poemas y antipoemas, pero que ha ido adquiriendo cada vez mayor dinamismo y energía. De ello da cuenta el segundo volumen de sus Obras completas \& algo $†$ (2011), donde se señala la imposibilidad de recoger en su totalidad y en todos sus formatos el conjunto de su trabajo visual y objetual.

En mi opinión, el proyecto antipoético como virus mutante y terriblemente peligroso puede hacerse legible también en términos de crítica contemporánea, en particular a partir del término radicante que aportó Nicolas Bourriaud en 2009 como explicación del modelo relacional que había desarrollado en un ensayo anterior (2006 [1998]) y que le permite abordar de modo sugestivo las condiciones tanto de creación como de recepción del arte contemporáneo. Vinculado al concepto de rizoma, del que vendría a ser su ulterior desarrollo, ser radicante -"término que designa un organismo que hace crecer sus raíces a medida que avanza" (22)- significa para Bourriaud "poner en marcha las propias raíces en contextos y formatos heterogéneos, negarles la virtud de definir completamente nuestra identidad, traducir las ideas, transcodificar las imágenes, trasplantar los comportamientos, intercambiar en vez de imponer" (22). En ese sentido además, sugiere Bourriaud, el artista devendría "semionauta" al "producir itinerarios en el paisaje de los signos" (43), es decir, al convertirse en inventor de "recorridos dentro del paisaje cultural" (43), nómada recolector de signos.

La obra de Parra ha ido trazando desplazamientos de una forma a otra que resultan muy notables. La reutilización de escritos parrianos en contextos nuevos es uno de sus aspectos constantes, que en su momento abordé como forma autotextual (2001) a través o bien de autocitas o citas literales parciales, o bien de variantes o citas referenciales parciales, pero la atención a esos desplazamientos desde categorías del arte contemporáneo -en particular lo radicante en tanto que aquello que propone un sujeto nómada, el que insiste en el itinerario, en el recorrido- permite pensar la producción parriana en la era de la globalización, lo que nos estaría llevando a encrucijadas epistemológicas capitales, porque puede ser leída a la luz de las nuevas categorías críticas, de las que visibiliza sus posibilidades al aportar espacios (anti)poéticos inéditos. 
Desde ellos, justamente, podemos decir que Parra, como todos los grandes, nos ha enseñado a leer el futuro (y tal vez, también el presente), aunque, para intranquilidad y gozo nuestros, no nos deje estar seguros: "DISCO RAYADO/ No veo para qué tanta alharaca:/ Ya sabemos que el mundo se acabó".

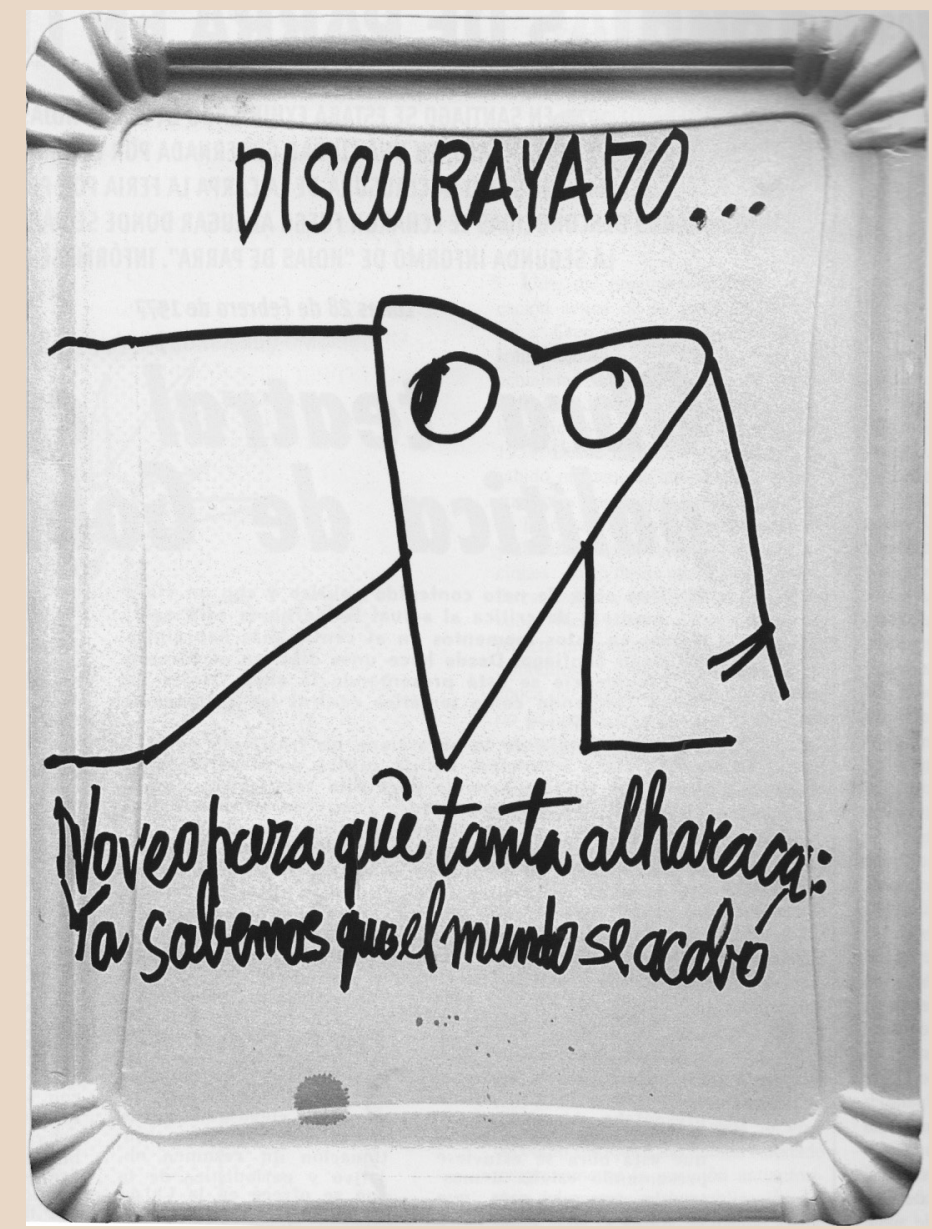

(Parra, 2004: 53) 


\section{REFERENCIAS}

Baricco, A. (2008 [2006]). Los bárbaros. Ensayo sobre la mutación. Traducción de Xavier González Rovira. Barcelona: Anagrama.

Binns, N. (1999). Un vals en un montón de escombros. Poesía hispanoamericana entre la modernidad y la postmodernidad (Nicanor Parra, Enrique Lihn). Bern: Peter Lang.

Bourriaud, N. (2006 [1998]). Estética relacional. Traducción de Cecilia Beceyro y Sergio Delgado. Buenos Aires: Adriana Hidalgo. (2009). Radicante. Traducción de Michèle Guillemont. Buenos Aires: Adriana Hidalgo.

Brea, J. L. (2007). Cultura_RAM. Mutaciones de la cultura en la era de su distribución electrónica. Barcelona: Gedisa.

(2010). Las tres eras de la imagen (imagen-materia, film, e-image). Madrid: Akal.

Calderón, A. (1970). “Nicanor Parra, un ejercicio respiratorio”. Aisthesis 5, 255260.

Fernández Mallo, A. (2008). “Apología del error”. El País. Suplemento "Babelia”, 2 de febrero de 2008. En http://www.elpais.com/articulo/semana/Apologia/ error/elpepuculbab/20080202elpbabese_1/Tes

Foucault, M. (2002 [1975]). Vigilar y castigar. Nacimiento de la prisión. Traducción de Aurelio Garzón del Camino. Buenos Aires: Siglo XXI.

Gache, B. (2006). Escrituras nómades. Del libro perdido al hipertexto. Gijón: Trea.

García Canclini, N. (2003 [1989]). Culturas híbridas. Estrategias para entrar y salir de la modernidad. México: Grijalbo.

García Fernández, E., Sánchez, S.; Marco, M. y Urrero, G. (2006). La cultura de la imagen. Madrid: Fragua.

Godina Herrera, C. (2006). "El panóptico moderno". A Parte Rei. Revista de Filosofía 46 (julio de 2006). En http://serbal.pntic.mec.es/ cmunoz11/godina 46.pdf

Maffesoli, M. (2004). El nomadismo. Vagabundeos iniciáticos. Traducción de Daniel Gutiérrez Martínez. México: FCE.

Marras, S. (2012). Materiales de demolición. Documental de 29 minutos de duración. En http://vimeopro.com/ornitorrinco/documentales-sergio-marras

Mestre, J. C. (2011). "Entrevista”. En P. H. Riaño y Soledad Pino: "El poeta que liberó a la poesía”. Público.es, 2 de diciembre de 2011. En http://www.publico. es/culturas/410133/el-poeta-que-libero-a-la-poesia

Mitchell, W. J .Th. (1994). “The pictorial turn”. Picture Theory: Essays on Verbal and Visual Representation. University of Chicago Press.

Molinuevo, J. L. (2006). La vida en tiempo real. La crisis de las utopías digitales. Madrid: Biblioteca Nueva.

Mora, V. L. (2012). El lectoespectador. Barcelona: Seix Barral. 
Noguerol Jiménez, F. (1999). "Híbridos genéricos: la desintegración del libro en la literatura hispanoamericana del siglo XX". Rilce 1, 239-250.

Parra, N. (1954). Poemas y antipoemas. Santiago de Chile: Nascimento. (1972). Artefactos. Santiago de Chile: Ediciones Nueva Universidad. (1983). Chistes parra desorientar a la polića poesía. Introducción de Enrique Lihn. Santiago de Chile: Galería Época. (2004). Especial Parra. The Clinic. Santiago de Chile, 21 de octubre. (2006). Obras completas \& algo † (1935-1972). Edición supervisada por el autor, asesorada y establecida por Niall Binns, al cuidado de Ignacio Echevarría. Prefacio de Harold Bloom. Prólogo de Federico Schopf. Tomo I, Barcelona: Galaxia Gutenberg-Círculo de Lectores.

(2011). Obras completas \& algo † (1976-2006). Edición establecida y anotada por Niall Binns e Ignacio Echevarría, con la colaboración de Adán Méndez. Tomo II, Barcelona: Galaxia Gutenberg-Círculo de Lectores.

Pérez Jiménez, J. C. (1996). Imago Mundi. La cultura audiovisual. Madrid: Fundesco.

Pérez López, M. Á. (2001). Introducción a Páginas en blanco. Salamanca: Ediciones Universidad de Salamanca/ Patrimonio Nacional, pp. 7-109. (2003). "La autotextualidad en Nicanor Parra: acotar/ agotar/ reciclar". Anales de Literatura Chilena 4, 165-175.

Piña, C. (2013). "La incidencia de la posmodernidad en las formas actuales de narrar". Cuadernos del CILHA [online] 2, 16-37. En http://www.scielo.org. ar/scielo.php?pid=S185296152013000200003\&script=sci_arttext

Rodríguez de la Flor, F. (2011). Giro visual. Salamanca: Delirio.

Shapton, L. (2010). Artefactos importantes. Traducción de Víctor Manuel García de Isusi. Barcelona: Duomo.

Tejeda, J. G. (2012). "Mis artefactos con Nicanor Parra". Quinchamali 8, 24-27.

Triviños, G. (2002). "Dirección obligada”. En Nicanor Parra: Artefactos visuales. Dirección obligada (pp. 10-13). Catálogo de la exposición. Universidad de Concepción: Dirección de Extensión/ Pinacoteca. (2010). “Putas, antipoetas y bisontes: penúltima versión". En la página dedicada a Nicanor Parra por la Biblioteca Virtual Miguel de Cervantes: http://crc.cervantes.es/literatura/escritores/parra/acerca/trivinos.htm

Vásquez Rocca, A. (2004). "Antipoesía y deconstrucción; Parra, artefactos dramáticos y recuperación del habla empírica". Poesía VersOados. En http:// www.filosofia.tk/versoados/articulos/articulo_antipoesia.htm

(2012). "Nicanor Parra: Antipoemas, parodias y lenguajes híbridos; de la antipoesía al lenguaje del artefacto". Almiar 62. En http://www.margencero.com/almiar/nicanor-parra-antipoemas-antipoesia/

Winock, M. (2010). El siglo de los intelectuales. Traducción de Ana Herrera. Barcelona: Edhasa. 